\title{
A STUDY OF EIGHTY-FOUR CASES OF DELAYED MUSTARD GAS KERATITIS FITTED WITH CONTACT LENSES*
}

$$
\text { IDA MANN }
$$

SINCE 1937, when the condition of delayed mustard gas keratitis was first beginning to be recognised, I have had an opportunity of examining a relatively large number of cases. Of these, 84have passed through the Contact Lens Clinic at Moorfields in order to be fitted by Dr. Dallos and others. They form the subject of this study and I am deeply indebted to those surgeons $\dagger$ who passed them on to me, for permission to use their cases in this analysis.

Since these form, as far as I know, the only large group of cases of what is obviously a disease process which is new and whose end results and prognosis are not yet fully known, it would seem desirable to make an interim study of them and of the results of treatment to the present time.

The series will give us some information on certain points associated with the wearing of contact lenses, which were up to now not clear. It will provide data on, among others, the following questions:- - How long elapsed between the original gassing and the first of the recurrent ulcers? What improvement, if any, in visual acuity was obtained by contact lenses? What was the tolerance of the patients for contact lenses? Did recurrent ulceration continue after wearing contact lenses? Were the patients able to return to work?

\section{The history of the condition when first seen}

All the 84 patients gave a history of exposure to mustard gas in 1917 or 1918. They were between the ages of 42 and 63 at the end of 1943. The majority were between 44 and 48 years old and so had been between 19 and 23 years old at the time of the gassing. Slightly more than half the total were gassed in 1917, the rest in 1918.

The diagnosis was made on the history and on the finding of the typical mustard gas scars with corneal degeneration (fat and cholesterin), varicose conjunctival and corneal vessels and avascular scars on the interpalpebral conjunctiva. These changes, first

* Received for publication, July 15, 1944.

† Messrs. Greeves, Juler, Whiting, Doyne, Davenport, Stallard, Law, King, Lister, Ridley 
pointed out by Phillips in 1940 and subsequently confirmed experimentally on rabbits by other workers (Mann and Pullinger, etc.) were present in all the cases. There is no need to describe them here, as they are now well known; though it is possible that cases are still being missed, since they are still appearing and usually do not volunteer the history of gassing unless this is asked for. The patient does not generally conrect the delayed keratitis with the exposure to gas. Indeed, of the 84 patients under review, 76 considered that they had recovered completely from the gas. They did not notice anything, except the need for rather frequent changes of glasses in some cases, until the ulceration stage of the delayed keratitis began. This had been treated simply as "recurrent corneal ulcers.".

The time of onset of the first ulceration following the initial healing is of interest in bringing out the long quiescent interval. Only eight of the patients stated that the sight of one or both eyes had never been so goód as before the gassing and that they had had some sort of eye trouble ever since. Four of these eight have had repeated slight breakdowns ever since 1919. This is, however, exceptional. Usually the only complaint is of altering refraction, this often being characterised by the appearance of and increase in a horizontal plus cylinder, due to slow alteration in curvature of the transverse scar in the cornea. The accompanying graph shows the distribution of the first onset of trouble (delayed keratitis) through the years 1920-1943 of the remaining 76 patients. It will be seen that sporadic cases occurred until 1931

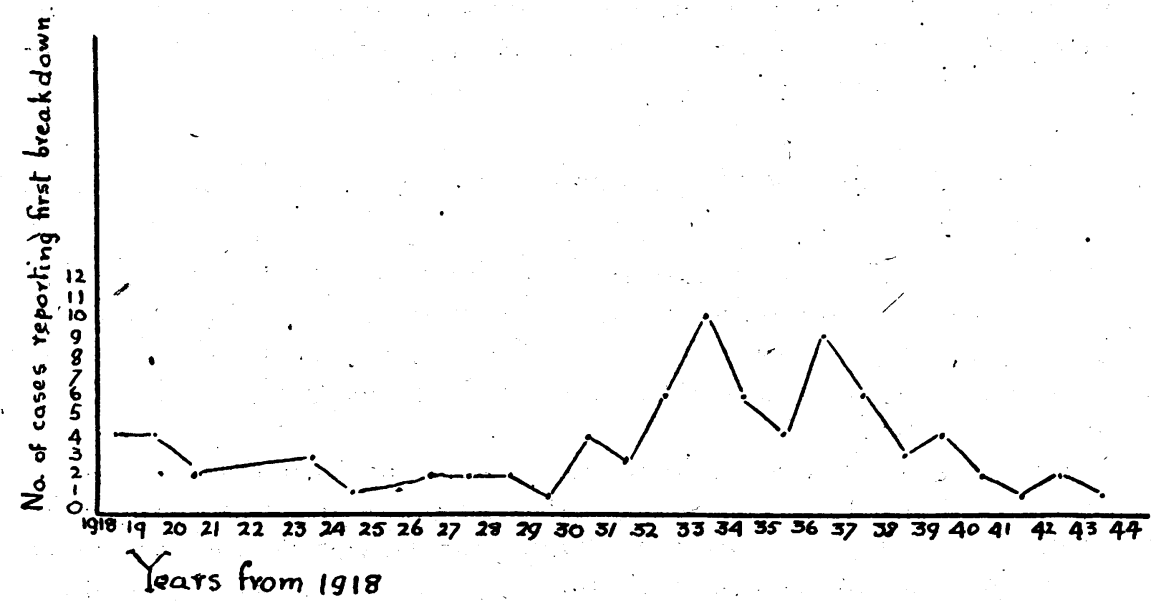

Graph showing distribution of onset of delayed keratitis in 82 cases. Two of the 84 did not remember the date of first onset of trouble after apparent cure. Four stated that they had had continuous trouble from the time of gassing and four had had a slight breakdown within. a year: 
and that after that date there was a steep rise lasting until 1937, 1933 and 1936 being the peak years.

The recurring ulcers heal but tend to leave facetted scars which gradually diminish visual acuity. The time in hospital immediately after the gas exposure varies from two months to two years in cases with severe chest symptoms as well. The average stay for the group is $6 \cdot 3$ months. No case of delayed keratitis has ever been seen in a patient whose initial ocular symptoms lasted less than eight weeks.

A typical history is that of a man, now aged 45 , of whom we possess an almost continuous record. He was gassed in 1918 and was severely ill for two morths and convalescent for some time after that. He apparently recovered and returned to his trade of wood turning, which he followed without trouble until 1928. He then sustained a slight injury to the right eye, which produced an ulcer.- This history of first onset of ulceration of the unstable scar following a minor injury is common. In some instances it is misleading, as the sensation of a beginning ulcer is very like that of a small foreign body. In this instance it is probably true, since no further trouble occurred in this eye for six years. After the ulcer had healed in 1928 the patient's visual acuity was reduced to $6 / 12$, as a small facetted scar was left. The visual acuity in the left eye was $6 / 6$. This had dropped to $6 / 9$ in 1932 without ulceration, but subsequently improved again slightly to $6 / 6^{\circ}$ in 1934. The right eye began to give serious trouble in 1934 when acuity was reduced by recurrent ulceration to $3 / 60$. This improved to $6 / 18$ the following year, but relapses occurred in 1937 and it fell to $3 / 60$ again. A contact lens was fitted in November, 1937, which improved the eye to $6 / 12$. Ulceration recurred once in 1938 , reducing the sight to $6 / 60$ with the contact lens, but this has now improved to $6 / 18$ and no further breakdown has occurred. The left eye had an attack in 1937 and was reduced to 6/9, improved to $6 / 6$ with a contact lens. A severe breakdown occurred in 1939 and vision was temporarily down to $4 / 60$. This eye has also remained well and with a contact lens is $6 / 6$ again. The man wears his contact lenses the whole day and is now perfectly comfortable. The corneae show typical scars and are insensitive. This is almost always the case and in part explains the usual excellent tolerance for contact lenses.

This history with its long interval, its repeated attacks and its fluctuating but slowly deteriorating visual acuity, relieved by wearing contact lenses, is typical of roughly 46 per, cent. of the cases. What their subsequent fate will be we do not yet know. That wearing contact lenses does not entirely prevent breakdown and further deterioration of sight seems certain, but it is equally 
certain that in a number of cases retention of visual acuity and continuance in work has been made possible for many years (up to seven years, at present). What we do not know is whether earlier fitting would have prevented or retarded breakdown. The relapses mostly began in 1933-6, as we have seen, and our first cases were fitted in 1937 .

\section{Improvement in visual acuity from contact lenses}

This was present in all but two of the cases. Of these two, one had exceptionally opaque central scars and in the other there was a large hysterical element. In the remainder the improvement was usually dramatic, since the loss of acuity is due more to the unevenness of the corneal surface than to the opacity of the scars. Some typical cases are set down in the table below.

TABLE I - Improvement in visual acuity

\begin{tabular}{|c|c|c|c|c|c|c|}
\hline \multirow{2}{*}{$\begin{array}{l}\text { Date of } \\
\text { first } \\
\text { relapse }\end{array}$} & \multirow{2}{*}{$\begin{array}{l}\text { Present } \\
\text { age of } \\
\text { patient }\end{array}$} & \multirow{2}{*}{$\begin{array}{c}\text { Date of } \\
\text { contact } \\
\text { lens } \\
\text { trial. }\end{array}$} & \multicolumn{2}{|c|}{$\begin{array}{l}\text { v.A. after spectacle } \\
\text { correction }\end{array}$} & \multicolumn{2}{|c|}{$\begin{array}{c}\text { V.A. with } \\
\text { contact lenses }\end{array}$} \\
\hline & & & $\mathbf{R}$ & $L$ & $\mathbf{R}$ & L \\
\hline 1923 & 43 & 1943 & $\begin{array}{l}\text { fingers } \\
\text { at } \frac{1}{2} \cdot m \text {. }\end{array}$ & $\begin{array}{l}\text { fingers } \\
\text { at } 1 \mathrm{~m} .\end{array}$ & $3 / 36$ & $6 / 24$ \\
\hline 1923 & 45 & 1940 & $6 / 60$ & $6 / 60$ & $6 / 12$ & $6 / 12$ \\
\hline 1927 & 58 & 1941 & Hd. Mvts. & Hd. Mvts. & $6 / 36$ & $6 / 36^{\circ}$ \\
\hline 1927 & 52 & 1941 & $6 / 36$ & $6 / 6$ & $6 / 9$ & $6 / 6$ \\
\hline 19928 & 45 & 1937 & $3 / 60$ & $6 / 9$ & $6 / 12$ & $6 / 6$ \\
\hline 1932 & 50 & 1942 & $<6 / 60$ & $<6 / 60$ & $6 / 36$ & $6 / 24$ \\
\hline 1932 & 46 & 1941 & $6 / 24$ & $6 / 60$ & $6 / 12$ & $6 / 9$ \\
\hline 1932 & 50 & 1939 & $<6 / 60$ & $<6 / 60$ & $6 / 36$ & $6 / 24$ \\
\hline 1933 & 57 & 1942 & cts. fgs. & cts. fgs. & $6 / 12$ & $3 / 60$ \\
\hline 1933 & 47 & 1940 & $<6 / 60$ & $<6 / 60$ & $6 / 18$ & $6 / 24$ \\
\hline 1933 & 47 & 1939 & $6 / 36$ & $6 / 24$ & $6 / 12$ & $6 / 12$ \\
\hline 1933 & 47 & 1938 & $<6 / 60$ & cts. fgs. & $6 / 18$ & $6 / 24$ \\
\hline 1934 & 46 & 1941 & $<6 / 60$ & $<6 / 60$ & $6 / 12$ & $6 / 9$ \\
\hline 1934 & 51 & 1940 & $6 / 18$ & $4 / 60$ & $6 / 12$ & $6 / 12$ \\
\hline 1934 & 45 & 1939 & $2 / 60$ & $3 / 60$ & $6 / 12$ & $6 / 18$ \\
\hline 1935 & 46 & 1942 & $6 / 24$ & $6 / 60$ & $6 / 12$ & $6 / 24$ \\
\hline 1936. & 53. & 1943 & $<6 / 60$ & $6 / 60$ & $6 / 18$ & $6 / 9$ \\
\hline 1936 & 46 & 1943 & $6 / 9$ & $6 / 36$ & $6 / 6$ & $6 / 9$ \\
\hline 1938 & 56 & 1943 & $4 / 60$ & $4 / 60$ & $6 / 36$ & $6 / 24$ \\
\hline 1939 & 55 & 1940 & $<6 / 60$ & cts. fgs. & $6 / 18$ & $6 / 24$ \\
\hline & & & $-\quad \vdots$ & & & \\
\hline
\end{tabular}

These'twenty cases, showing relapses of 5 to 21 years duration, are typical. These twenty (and others) are wearing their contaat lenses for 8 to 16 hours a day. 


\section{History subsequent to fitting of contact lenses}

a. Length of wear. Mustard gas cases usually have very good tolerance for contact lenses, both on account of the relative insensitivity of their corneae and of the very great improvement in visual acuity; which acts as a spur to success in many cases.

The length of wear can be classified into eight hours a day or over (i.e., allowing for a day's work); between five and eight hours; under five hours and not at all. One can also classify according to the number of years the lenses have been in use. The 84 cases (analysed in the following table) demonstrate that in 39 instances the lenses are worn with comfort during the working day. Of these 39,17 wear them the whole of their waking life, 10 wear them from 10-12 hours a day and the rest for periods varying from 8-10 hours.

Three of the 84 men have died since being fitted. Four had had one eye excised before being fitted. Five men could not wear the lenses at all and eight could not wear them enough to be much good. In 20 cases the details are not complete.

- TABLE II.-Hours per day and yegrs of wear (contact lenses)

\begin{tabular}{|c|c|c|c|c|c|c|}
\hline \multirow{2}{*}{$\begin{array}{l}\text { Years in } \\
\text { wear }\end{array}$} & \multirow{2}{*}{$\begin{array}{c}\text { No. of } \\
\text { men }\end{array}$} & \multicolumn{5}{|c|}{ Hours of wear per day } \\
\hline & & $8-16$ & $5-8$ & Under 5 & Not at all & Not known \\
\hline $\begin{array}{l}<1 \text { year... } \\
1 \text { year } \ldots \\
2 \text { years } \ldots \\
3 \text { years } \ldots \\
4 \text { years } \ldots \\
5 \text { years } \ldots \\
6 \text { years } \ldots \\
7 \text { years ... } \\
\text { not known }\end{array}$ & $\begin{array}{r}7 \\
6 \\
12 \\
10 \\
15 \\
13 \\
4 \\
6 \\
11\end{array}$ & $\begin{array}{l}2 \\
4 \\
7 \\
6 \\
9 \\
8 \\
1 \\
1 \\
1\end{array}$ & $\begin{array}{l}1 \\
2 \\
3 \\
2 \\
1 \\
1 \\
- \\
-1\end{array}$ & $\begin{array}{l}1 \\
1 \\
2 \\
1 \\
- \\
-1 \\
2\end{array}$ & $\begin{array}{l}- \\
\frac{-}{-} \\
\frac{1}{1} \\
\frac{1}{3}\end{array}$ & $\begin{array}{l}\frac{3}{1} \\
\frac{1}{3} \\
4 \\
2 \\
4 \\
4\end{array}$ \\
\hline $1937-1944$ & 84 & 39 & 11 & 8 & 5 & 21 \\
\hline
\end{tabular}

A consideration of the occupations of the 39 successful cases shows them to be mostly doing fairly intelligent work. They include a schoolmaster, three clerks, a postmaster, a postman, a telephone operator, a printer, a rating and valuation officer, a motor engineer, a radio engineer, a works foreman, an inspector 
in an aircraft factory, two taxi drivers, a railway foreman, a guard, a bus conductor, two restaurant keepers, a motor body builder, a cabinet maker, a wood turner, a carpenter and a bricklayer. Only two are ordinary labourers. Three are looked after by St. Dunstan's and do handicrafts, since even with contact lenses their sight is very variable and they are deteriorating. The majority are well and in work and very satisfied with their lenses.

Of these 39 successful cases, 20 have had one or more relapses since wearing the lenses. Thirteen of these have had far fewer relapses than before wearing the lenses and many have only had one slight one since fitting. Four state that they have had more relapses since wearing contact lenses. In, them, and in three others, visual acuity is gradually deteriorating, although they are able to wear their lenses for most of the day.

In Table II it can be seen that five patients were unable to wear their lenses at all. Of these, two were at St. Dunstan's when fitted and got very little improvement in visual acuity. They were working as blind men and had no incentive to persevere. Two others had severe relapses during and after their fittings and are technically blind. One of these two had to have an iridectomy on one eye and a tarsorrhaphy on the other and never managed his lenses at all. The other had a tarsorrhaphy and was sent to St. Dunstan's. The remaining one of the five, who was of independent means, with no need to work, had also frequent relapses.

Eight patients (Table II) wore their lenses less than five hours a day. One of these was the hysteric (mentioned on p. 444), another was neurotic, with frequent relapses, and three saw relatively well with spectácles and preferred to wear them. One has only had. his lenses a month and is. shaping well. One has relapsed repeatedly and no details are known of the eighth.

b. Relapses. Although relapses do occur in contact lens wearers, they tend to be less frequent, since the glass protects the insensitive cornea from small injuries and any relapses which do occur are due to the continuance of the deep pathological changes in the cornea rather than to surface irritation. Of the 84 cases, 25 had no relapses at all after fitting, 49 had relapses (of these. 4 had one only, and 16 slight only; while 19 were of moderate severity and 10 were severe). The history of 10 is uncertain, but they have made no complaint. If severe relapses occur, visual acuity, even with contact lenses, falls in the course of years. We do not know the end result, but Descemetoceles may occur (this does not preclude the wearing of a contact lens), and in very rare cases perforation. There is one smáll Descemetocele (with visual acuity $6 / 24)$, but no perforation, in this series. 


\section{Treatment other than contact lenses}

In the course of fitting some of these patients, and afterwards, relapses occurred, and various cther treatments had to be resorted to. The commonest lesions observed were :

(1) Small shallow ulcers. " These heal fairly quickly with mild mydriatics and heat. Hyoscine and diathermy were usually given as a routine, but some of the patients stated that they healed practically as well with hot bathing at home and no drops.

(2) Deeper ulcers, discharging cholesterin and fatty debris from the base. These take longer to heal and may require tarsorrhaphy. They are sometimes hastened by gentle curetting

(3) Superficial plaques, raised from the surface, of degenerative material. These may mechanically interfere with the wearing of a contact lens and should be scraped off. They are usually easily removed, and much relief is experienced by the patient.

(4) Varicose vessels and blood islands. Sometimes the abnormal vessels at the limbus and just on the cornea become very dilated. The circulation may cease and the distended ends of the vessels may remain like small red blisters. These should be pricked and the blood coaxed out of them. If it is still circulating the feeding vessels should be divided with a fine cautery or a peritomy performed. The relief obtained lasts a long time, though there is a tendency for slow reappearance in adjacent zones.

\section{Summary}

Eighty-four cases of delayed mustard gas keratitis are reviewed. They were all fitted with contact lenses, some of them seven years ago. Thirty-nine of the patients wear their lenses from eight to sixteen hours a day, 11 from five to eight hours, eight under five hours, five not at all and in 21 cases the time is not known. The visual acuity in all but two was markedly improved. In twentyfive cases there was no further relapse after fitting, in four cases one relapse only, in 16 very slight relapses and in 10 only were the relapses severe. The age of onset of the symptoms, the occupation of the patients and the treatment of intercurrent complications is discussed.

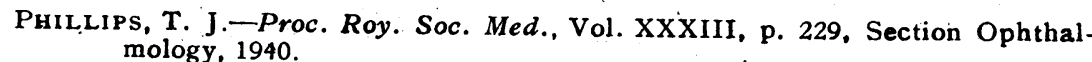

MANN and PULinger.-Proc. Roy. Soc. Med., Vol. XXXIII, p. 229, 3, Section , Ophthalmology, pp. 1-16, 1942.

Brit. Jl. Ophthal., Vol. XXVI, p. 503, 1942.

Brit. Med. Jl., March 14, Vol. I, p. 353, 1942.

Jl, Path. and Bact., Vol. IV, No. 2, p. 151, 1943. 